\title{
Anatomical organization of aortic arch variations in the India: embryological basis and review
}

\author{
O rganização anatômica das variações do arco aórtico na população indiana: \\ base e revisão embriológica
}

\author{
Soubhagya R. N ayak, M angala M. Pai, Latha V. Prabhu, Sujatha D 'C osta, Prakash Shetty*
}

\begin{abstract}
O bjectives: To determine the percentage and type of aortic arch variationsin Indian subjects and their clinical and surgical importance and embryological basis.

Patients and methods: In our investigation, branching patterns of the aortic arch were studied in 62 formalin-fixed cadavers of both sexes of Indian origin, aged 45-79. The dissections were carried out in formalin-preserved cadavers and the aortic arch variations were observed after exposing thethoracic and cervical region during routine dissection of undergraduate students of Indian origin in Kasturba M edical College, M angalore.

Results: The usual three-branched aortic arch was found in 56 cadavers $(91.4 \%)$; variations were found in six cadavers $(9.6 \%) ; 4.8 \%$ presented common origin of the carotid arteries; $1.6 \%$ had biinnominate sequence, and the same specimen had left coronary artery arising from arch of aorta directly; $1.6 \%$ presented right subclavian artery arising directly from the aorta; $1.6 \%$ had left vertebral artery a branch of aortic arch. Five out of six cadavers with anomal ous aortic arch branching pattern were females. O ne male cadaver presented anomalous origin of left vertebral artery directly from the arch.

C onclusion: The wide spectrum of variations in the anatomical arrangements of the aortic arch branches in the Indian population was at par with other populations of the world. Although anomalous origins of the aortic arch branches are merely anatomic variants, accurate information about them is vital for vascular surgery in the thorax, head and neck region.
\end{abstract}

Key words: Aortic arch, vertebral artery, brachiocephalic trunk, variations. * Department of Anatomy, Centre for Basic Sciences, Kasturba Medical
College, Bejai, Mangalore, Karnataka, India.

Article submitted March 17, 2006, accepted June 06, 2006.

\section{Resumo}

O bjetivos: D eterminar a porcentagem e 0 tipo de variações do arco aórtico em indivíduos indianos, bem como sua importância clínica e cirúrgica e base embriológica.

Pacientes e métodos: Em nossa investigação, os padrões de ramificação do arco aórtico foram estudados em 62 cadáveres fixados em formalina de ambos os sexos, de origem indiana e com idade entre 45 e 79 anos. As dissecações foram realizadas em cadáveres preservados em formalina, e as variações do arco aórtico foram observadas após a exposição das regiões torácica e cervical durante a dissecação de rotina de alunos da graduação do Kasturba M edical College, M angalore, Índia.

Resultados: 0 arco aórtico normal de três ramificações foi encontrado em 56 cadáveres (91,4\%); as variações foram encontradas em seis cadáveres $(9,6 \%) ; 4,8 \%$ apresentavam origem comum das artérias carótidas; 1,6\% tinham seqüência binominada, e o mesmo espécime tinha a origem da artéria coronária esquerda diretamente no arco aórtico; 1,6\% apresentavam a origem da artéria subclávia direita diretamente na aorta; 1,6\% tinham como ramificação do arco aórtico uma artéria vertebral esquerda. Cinco de seis cadáveres com padrão de ramificação anômalo do arco aórtico eram do sexo feminino. U m cadáver do sexo masculino apresentou origem anômala da artéria vertebral esquerda diretamente no arco.

Conclusão: 0 amplo espectro de variações nos padrões anatômicos das ramificações do arco aórtico na população indiana estava em concordância com outras populações mundiais. Embora as origens anômalas das ramificações do arco aórtico sejam meramente variações anatômicas, informações precisas sobre elas é essencial para a cirurgia vascular na região do tórax, cabeça e pescoço.

Palavras-chave: Arco aórtico, artéria vertebral, tronco braquiocefálico, variações.

\section{Introduction}

The anomalies of branches arising from the aortic arch are due to variations in the extent of the fusion process and absorption of someof the aortic archesinto the aortic sac. Increase and decrease in number of branches arising from the arch depend on such process. 
The great arteries of the thoracic region are well known for their variations. The aortic arch is one of them, with well known variations. The arrangement regarded as normal for humans is actually found more frequently than other types combined. In specimens of normal variety, the branches leave the arch in the following succession from left to right: left subclavian, left common carotid (LCC) and brachiocephalic trunk (with right common carotid and right subclavian as its derivatives). The variations of branches arising from aortic arches(Figure1) arewell known and documented by several authors in different races, such as Barry, ${ }^{1}$ Barewell, ${ }^{2}$ Birmingham, ${ }^{3}$ Brodie, ${ }^{4}$ Brown etal., ${ }^{5}$ D egaris et al., ${ }^{6} \mathrm{H}$ arley, ${ }^{7}$ Lize, $^{8} \mathrm{G}$ rande et al., ${ }^{9}$ Bhatia et al. ${ }^{10}$

Someauthors, such asBernardi et al., ${ }^{11}$ hypothesize that anomalous origins and the distribution of thelarge aortic arch vessels can cause changes in cerebral hemodynamicsthat may lead to cerebral abnormalities. The true value of detecting anomalous origins is the diagnostic gain prior to the surgery of supraaortic arteries. For casesin which thevertebral artery originates from the carotid artery or its branches, the ligation of

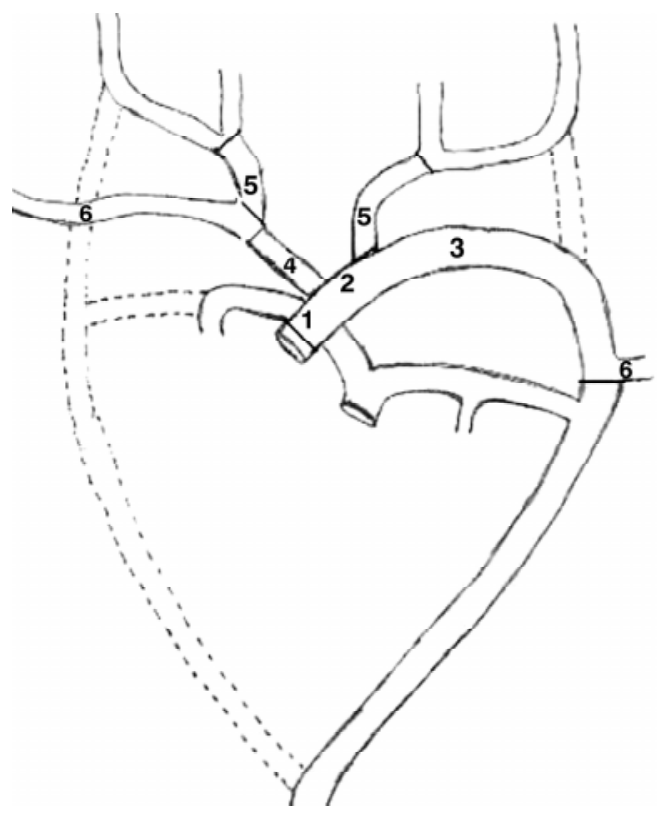

Figure 1 - D erivation of major arteries from aortic archesin normal case

1, 2, 3) Development into aortic arch. 4) Brachiocephalic trunk. 5) Common carotid arteries. 6) Subclavian artery. the common carotid artery may cause a compromise of the posterior fossa blood supply, as reported by Flynn et al. ${ }^{12} \mathrm{D}$ etailed knowledge of an anomalous origin of supraaortic arteries is also important for patients who have to undergo four-vessel angiography in an emergency, in order to rule out, for example, the possibility of intracranial aneurysm after subarachnoid hemorrhage. If the detection of a vertebral artery in the normal position is not possible, the presence of such a variant must be taken into consideration. ${ }^{13}$ The anatomic and morphologic variations of the aortic arch and its branches are significant for diagnostic and surgical procedures in the thorax and neck. If a right retroesophageal subclavian artery is diagnosed during aortic arch repair, corrective surgery should be considered. Intensive care patients should be screened before long term placement of nasogastric tube, in order to avoid fistulization and fatal hemorrhage. ${ }^{14}$ $\mathrm{M}$ omma et al. described that aortic arch anomalies are also associated with chromosome 22 q11 deletion. ${ }^{15}$

Thepresent study describestheaortic arch branching pattern in Indian subjects and discusses the findings according to their embryological, clinical and surgical implications.

\section{M aterials and methods}

During routine dissection conducted over 62 cadavers of both sexes (aged 45-79) of Indian origin at Kasturba $M$ edical College, $M$ angalore, the mediastinum wasopened and observationsweremade for abnormalities of the branching pattern of the aortic arch.

\section{Results}

In six cases (9.6\%), theabnormalitieswerefound in the branching pattern of the aortic arch. Of these three cases, $4.8 \%$ presented a common abnormality (the LCC artery as a branch of brachiocephalic trunk with different degrees of branching).

\section{Cases I, II, and III}

In these cases (Figures 2, 3, and 4) the LCC arteries were taking origin from the brachiocephalic trunk. In casel, theorigin of the LCC artery was very close to the stem, al most looked like a trident pattern arrangement. In case II, the origin of the LCC artery was slightly above the stem of the brachiocephalic trunk. 


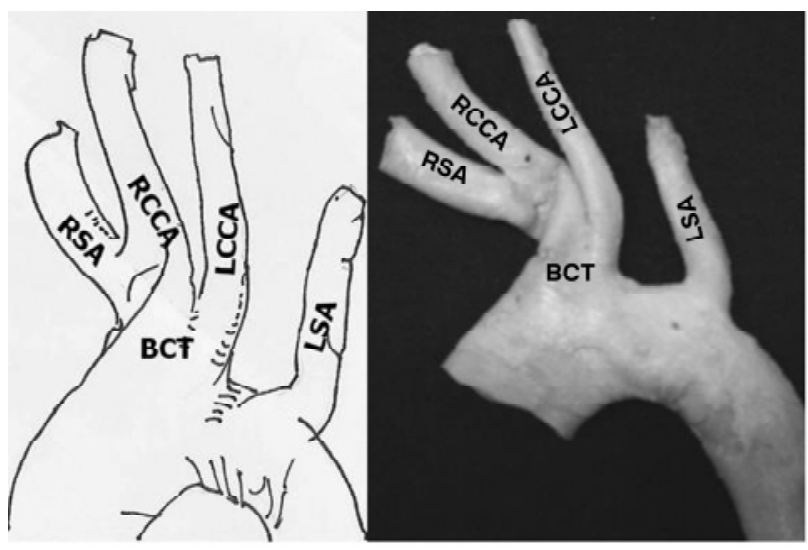

Figure 2 - Aortic arch variations, case I

$B C T=$ brachiocephalic trunk; $L C C A=$ left common carotid artery; LSA = left subclavian artery; RCCA = right common carotid artery; RSA = right subclavian artery.
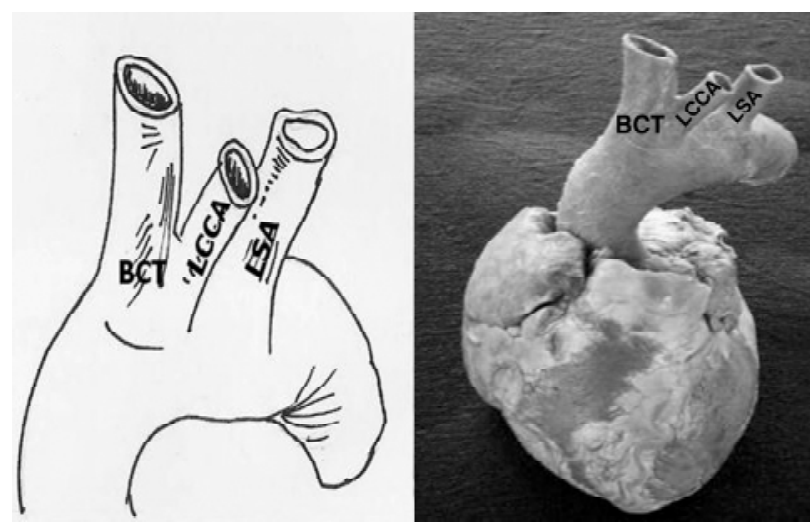

Figure 3 - Aortic arch variations, case II $\mathrm{BCT}=$ brachiocephalic trunk; $\mathrm{LCCA}=$ left common carotid artery; LSA = left subclavian artery.
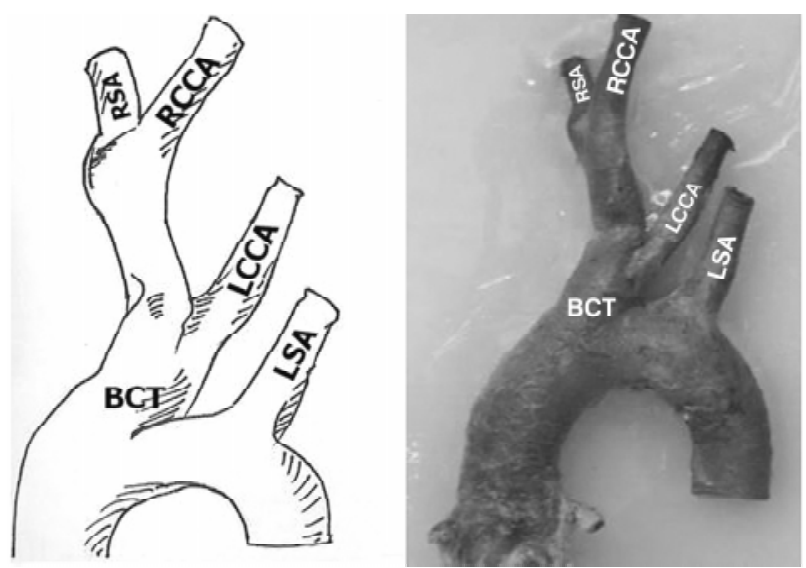

Figure 4 - Aortic arch variations, case III

$\mathrm{BCT}$ = brachiocephalic trunk; LCCA = left common carotid artery; LSA = left subclavian artery; RCCA = right common carotid artery; RSA = right subclavian artery.
In case III, the brachiocephalic trunk al so gave rise to the LCC artery, but the origin was higher than the previous two cases, the division of the right subclavian and right common carotid artery was even higher.

\section{Case IV}

In this case (Figure 5) there were only two trunks arising from thearch, left and right innominatearteries. Each onewasgiving riseto thesubclavian and common carotid arteries of therespectivesides. Theleft coronary artery was arising from the posterior aspect of the aortic arch.

\section{Case V}

In this case (Figure 6) the vertebral artery was a branch of the aortic arch, between the origins of LCC and left subclavian artery.

\section{A}
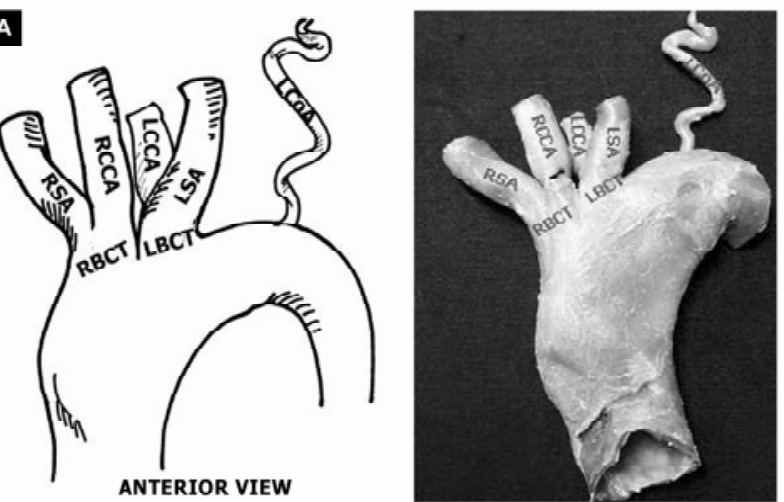

B
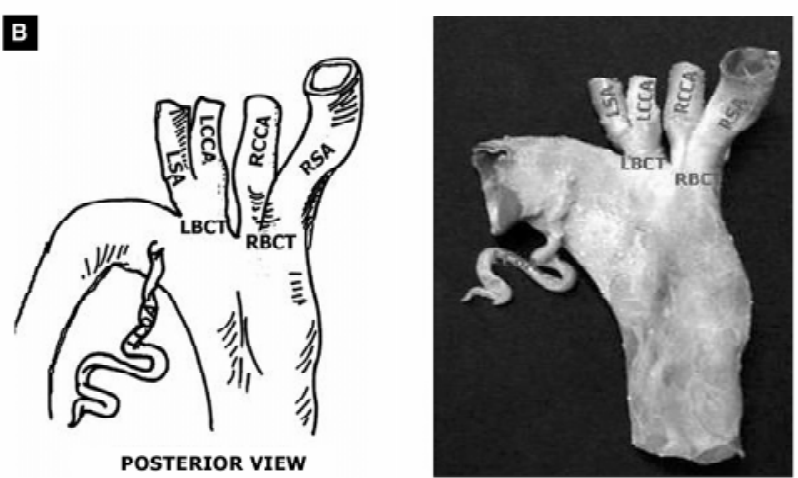

Figure 5 - Aortic arch variations, case IV . A) Anterior view. B) Posterior view

LBCT = left brachiocephalic trunk; LCCA = left common carotid artery; $\mathrm{LCoA}=$ left coronary artery; $\mathrm{LSA}=$ left subclavian artery; RBCT = right brachiocephalic trunk; RCCA = right common carotid artery; RSA = right subclavian artery. 


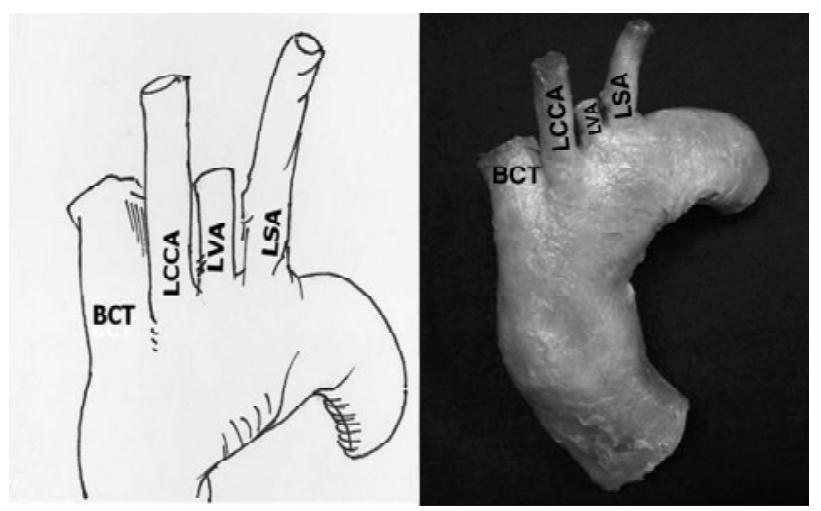

Figure 6 - Aortic arch variations, case $\mathrm{V}$

$B C T=$ brachiocephalic trunk; LCCA = left common carotid artery; LSA = left subclavian artery; LVA = left vertebral artery.

\section{Case VI}

Anomalous origin of right subclavian artery from the descending aorta, which courses behind the trachea and esophagus to reach the right axilla (Figure 7).

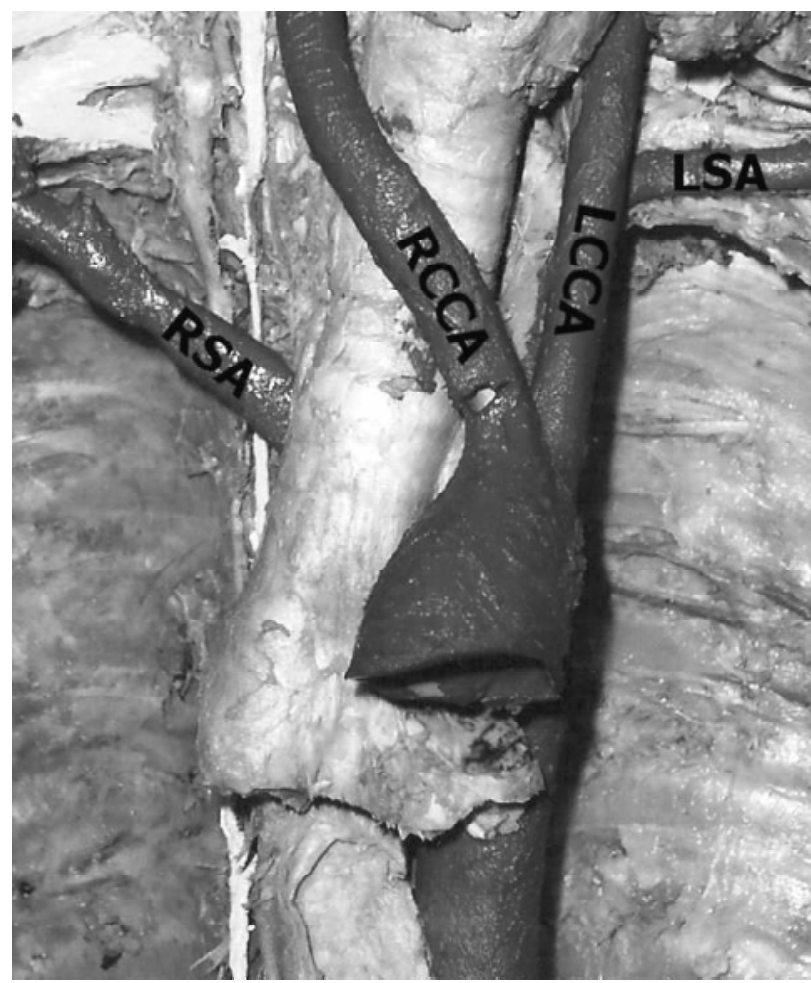

Figure 7 - Aortic arch variations, case $\mathrm{VI}$

LCCA = left common carotid artery; LSA = left subclavian artery; $\mathrm{RCCA}=$ right common carotid artery; $\mathrm{RSA}=$ right subclavian artery.

\section{Discussion}

The true value of detecting anomalous origins is in the diagnostic gain before vascular surgeries of supraaortic arteries, as variations of the branches of the aortic arch are likely to occur as a result of the altered development of certain branchial arch arteries during theembryonic period of gestation. ${ }^{10} \mathrm{~T}$ heapproximation of the LCC artery to the brachiocephalic trunk is an important observation while invading the aortic arch and its branches with instruments, since all cases are susceptible to surgical attack. ${ }^{10} \mathrm{~N}$ on-recognition of a critical aortic arch branch variation at surgery may causefatal consequences. ${ }^{16} \mathrm{~T}$ heangiographic detection of common brachiocephalic trunk may be a marker for thepresenceof accompanying congenital cardiac defects and coronary arterial abnormalities. U nderstanding the pathophysiological effects of the common brachiocephalic trunk is important when planning the palliative or corrective procedures, and when assessing the potential benefit of the surgical repair over thelong term. ${ }^{17}$

According to Anson et al., ${ }^{18}$ the normal three branched arrangement of the aortic arch is found in $64.9 \%$. An arrangement distinguished by reduction in the number of stems to two, both common carotid arteries arising from the innominate occurs in $27.1 \%$. Theright subclavian artery passesdorsal to theesophagus and the last branch of the aortic arch reaching theright upper extremity in $0.5 \%$. A bi-innominate sequence in which paired vesselsaretheonly derivatives of theaortic arch is found in $1.2 \%$. The left vertebral artery is the additional vessel arising from the arch in $2.5 \%$. In our study we found the following variations with different percentages: $4.8,1.6,1.6,1.6 \%$ respectively.

\section{Embryological basis of the variations in our study Case I, II, III}

C ase I. The left limb of the aortic sac normally forms the part of the arch that intervenes between the origins of the brachiocephalic trunk and the LCC artery. If the aortic sac fails to bifurcate into right and left limbs, then the LCC artery will connect to theaortic sac directly. That results in a common origin of the carotid arteries (COCA).

C ase II. The proximal part of the third aortic arch normally gets extended and absorbed into the left horn of aortic sac. If it gets absorbed into the right horn of the aortic sac, the branching pattern of 
the brachiocephalic trunk will be abnormal as in the above three cases.

\section{Case IV}

Theabnormal left brachiocephalic trunk wasformed by the fusion of the proximal part of the left third arch artery and left seventh intersegmental artery into thel eft fourth arch artery, which was responsible for the left subclavian artery and LCC artery arising from acommon trunk. T heleft coronary artery may bud from the aortic arch instead of the ascending aorta. This was an additional anomaly.

\section{Case V}

The left subclavian artery normally develops from left seventh intersegmental artery and the first part of the vertebral artery develops from the dorsal ramus of the seventh intersegmental artery (proximal to postcostal anastomosis). The left subclavian artery is only developed from the left seventh intersegmental artery.

In the present case the vertebral artery developed from the persistent sixth cervical intersegmental artery.

\section{Case VI}

Thisanomaly wascaused by the degeneration of the right fourth aortic arch, so that the right seventh cervical intersegmental artery and the right dorsal aorta caudal to it are continued as the right subclavian artery.

Anatomical and morphological variations of the vertebral artery are of great importance in surgery, angiography and all non-invasive procedures. ${ }^{19}$ According to Bernardi \& D elton, the abnormal origin of vertebral artery may favor cerebral disorders due to alterations in cerebral hemodynamics. ${ }^{11}$

Sometimesaorticarch anomaliesareclinically useful. Catheterization of the LCC artery arising from an innominate artery can be achieved without catheter exchange. ${ }^{20} \mathrm{~W}$ hen three of the four primary sources of cerebral blood flow arise from a single aortic branch, such as in the case of common origin of common carotid arteries, stenosis or occlusion of a common trunk can cause severe ischemic consequences. ${ }^{21}$ Komiyana et al. reported the incidence of arterial dissection of the vertebral artery of aortic origin and vertebral artery of subclavian origin. According to their studies, the left vertebral artery of aortic origin was associated with a significantly higher incidence of vertebral artery dissection than left vertebral artery of left subclavian artery origin and right vertebral artery of right subclavian origin. 22

In our study, the aortic arch branch variationswere observed in six cases (9.6\%). The percentage of aortic arch branch variations was not as high as the data provided by $\mathrm{G}$ rande et al. ${ }^{9}$ in Portuguese population and Bhatia et al. ${ }^{10}$ in South Australian population of European descent.

\section{Conclusion}

The wide spectrum of variations in the anatomical arrangements of the aortic arch branches in Indian population was at par with other populations of the world, but the percentage of anatomical variants was less comparative to other populations. Although anomalous origins of the aortic arch branches are merely anatomic variants, accurate information about them isvital for vascular surgery in thethorax, head and neck region.

\section{References}

1. Barry A. Theaortic arch derivatives in the human adult. Anat Rec. 1951;111(2):221-38.

2. Barwell. Abnormal origin of arteries from the aortic arch. Trans Pathol Soc Lond. 1867;18:68.

3. Birmingham A. Extreme anomaly of the heart and great vessels. J Anat Physiol. 1893;27:139-50.

4. Brodie G. Rare abnormality of the aortic arch. Lancet. 1888;2:971.

5. Brown JD, Brown FJ. Abnormal origin of the vessels from the arch of the aorta. Brit M ed J. 1868;1:632.

6. DeGaris CF, Black IH, Riemenschneider EA. Patterns of the aortic arch in American white and Negro stocks, with comparative notes on certain other mammals. J Anat. 1933;67:599-619.

7. H arleyH R. Thedevelopment and anomalies of the aortic arch and its branches. Br J Surg. 1959;46:561-73.

8. Lize I. Abnormal origin of the great blood vessels from the aortic arch. Folia M orphol (W arsaw). 1970;29:355-7.

9. GrandeN R, CostaeSilvaA, PereiraAS, AguasAP. Variations in the anatomical organization of the human aortic arch. $A$ study in a Portuguese population. Bull Assoc Anat ( $\mathrm{N}$ ancy). 1995;79(244):19-22.

10. BhatiaK, G habriel M N , H enneberg M. Anatomical variations in the branches the human aortic arch: a recent study of a South Australian population. Folia Morphol (W arsz). 2005;64(3):217-23.

11. Bernardi $L, D$ eton $P$. Angiographic study of a rare anomalous origin of the vertebral artery. N euroradiology. 1975;9:43-7. 
12. Flynn RE. External carotid origin of the dominant vertebral artery. Case report. J N eurosurg. 1968;29:300-1.

13. Lemke AJ, Benndorf $G$, Liebig T, Felix R. Anomalous origin of the right vertebral artery: review of the literature and case report of right vertebral artery origin distal to thel eft subclavian artery. AJNR Am J N euroradiol. 1999;20:1318-21.

14. Fazan VPS, Ribeiro RA, Ribeiro JAS, Rodrigues Filho OA. Right retroesophageal subclavian artery. Acta Cir Bras. 2003;18:54-6.

15. M omma K, M atsuoka R, Takao A. Aortic arch anomalies associated with chromosome 22q11 deletion (CATCH 22). Pediatr Cardiol. 1999;20:97-102.

16. Satyapal KS, Singaram S, Partab P, Kalideen JM, Robbs JV. Aortic arch branch variations - case report and arteriographic analysis. S Afr J Surg. 2003;41:48-50.

17. M oskowitz WB, Topaz 0 . The implications of common brachiocephalic trunk on associated congenital cardiovascular defects and their management. Cardiol Young. 2003;13: 537-43.

18. Anson BV, M cvay C B. Surgical anatomy. 5th ed. Philadel phia: W B Saunders; 1971.

19. M atula C, T rattnig S, T schabitscher M, D ay JD, Koos W T. The course of the prevertebral segment of the vertebral artery, anatomy and clinical significance. Surg N eurol. 1997;48(2): 125-31.
20. Carlson DH , M cD onald D G. Simplified catheterization of a left common carotid artery arising from theinnominatetrunk. Radiology. 1982;144:419.

21. AzakieA, M cElhinney D B, M essinaLM , Stoney RJ.C ommon brachiocephalic trunk: strategies for revascularization. Ann Thorac Surg. 1999;67(3):657-60.

22. Komiyama $\mathrm{M}, \mathrm{M}$ orikawa $\mathrm{T}, \mathrm{N}$ akajima $\mathrm{H}, \mathrm{N}$ ishikawa $\mathrm{M}$, Yasui T. H igh incidence of arterial dissection associated with left vertebral artery of aortic origin. $\mathrm{N}$ eurol M ed C hir (T okyo). 2001;41(1):8-11.

\section{Correspondence:}

Soubhagya R. N ayak

D epartment of Anatomy - K asturba M edical College 575004 - Bejai, M angalore, Karnataka, India

E-mail: ranjanbhatana@gmail.com 